\title{
ANALYSIS OF STICK SHOOTING IN OINA GAME USING THE BIOMECHANICAL PARAMETERS
}

\author{
Cristian VĂDUVA ${ }^{1}$, Gheorghe MONEA ${ }^{1}$, Mihnea MARIN²*, Ligia RUSU \\ 1 "Babeş Bolyai” University, Faculty of Physical Education and Sport, Cluj-Napoca, Romania \\ ${ }^{2}$ University of Craiova, Faculty of Mechanics, Craiova, Romania \\ ${ }^{3}$ University of Craiova, Faculty of Physical Education and Sport, Craiova, Romania \\ *Corresponding author: mihnea_marin@yahoo.com
}

DOI: $10.35189 /$ iphm.icpesk.2019.50

\begin{abstract}
Oina is our national sport, which has only been studied from the point of view of physical, technical and tactical preparation and the history of the game. The aim of this study is to make a biomechanical analysis of kinematic parameters of upper-limb angles (range of motion, speed and angular acceleration) and also to study the influence of these parameters when hitting the ball with a bat. Material and Methods: The study includes 22 athletes (7 boys and 15 girls, average age 30 years for boys and 17 years for girls). Using the VICON system, we recorded the trajectories of marked points, which were in accordance with the marker design. The data were analysed and we obtained information about the range of motion, angular speed and acceleration for these points when hitting with a bat. Results: After the analysis, we have observed that the angular speed of the right arm is 31.2\% more than the angle of the left arm, and the angular speed of the left elbow is $14.2 \%$ more than the right one. Conclusion: This evolution of angular speed requires the development of explosive muscle strength for the right arm, which limits injuries and increases the stability of kinetic chain for the right upper limb. This occurs in the strength-speed relationship. On the other side, for the left arm, the training must be centred on isometric contractions to increase stability in the left upper limb, because it has to regain strength from the contralateral upper limb.
\end{abstract}

Keywords: kinematic parameters, oina game, kinetic chain.

\section{Introduction}

Oina is not just a simple game, but the only Romanian national game conveyed to us by our ancestors throughout centuries of history. Starting from "a simple game for kids" (Buiac, 2018, p. 87), oina went through some important changes and developments. Over time, it grew more dynamic by the increase in the number of players from six to eight.

Nowadays, in Romania, there are no studies on the impact of the biomechanical parameters of oina players, the only references being related to physical training, the technique used during the game, tactical elements and historical development (Rafailescu \& Oprițescu, 1974, p. 33; Postolache, 2009, p. 11; Moje, Frangulea, Roată, \& Şiclovan, 2011, p. 73; Roată, 2018, p. 176).

The pitching in oina game has a specific profile and, for the coach, we could say that the elements making a pitcher effective are "velocity" and "accuracy". It is important to have a biomechanical study of motion in elite players to discern how they consistently throw fast pitches in the strike zone. Currently, there are no studies regarding this aspect in oina game, but a lot of measurements can be made for kinematic analysis in order to improve ball velocity. Higher ball velocity means higher kinetic values for the elbow and shoulder during pitching.

Purpose and hypothesis of the study

This study aimed to analyse the biomechanical motions involved in oina in order to enhance the effect of the actual hit of the ball from the standpoint of the ball trajectory, starting from the biomechanical analysis of the bat's motion during the game of oina.

The hypothesis of this research is that the sole movement of the bat can make all the difference in scoring during a game of oina.

Oina is in constant evolution, and the value of the teams fighting for the podium is close. The results of these two teams when playing "catch" are pretty much the same. The difference between their performances becomes obvious when hitting the ball with the bat. These simple observations led to the necessity of a study on the impact of the biomechanical motion of hitting the ball with an oina bat by measuring the mechanics of the motion itself. Another reason for this research is that, due to its complexity, lots of players do not hit the oina ball properly, whereas this research can be a starting point for proper training in order improve the players' performance.

Also, the goal of this study based on the biomechanical analysis of hitting the oina ball is to describe the body's natural motion and coordination during the game. 
At the same time, we could obtain information about the relationship between the rotational and linear components of weight transfer and about the specific interaction of segments involved in the kinetic chain.

\section{Material and Methods}

The research method consists in using the biomechanical analysis of motion when hitting with an oina-specific bat. The research was made by the Laboratory of Innovative Processes and Techniques in Bioengineering from the Research Infrastructure in Applied Sciences (INCESA) within the University of Craiova by means of a complex system of image capture and processing called VICON (2015) (Figure 1).

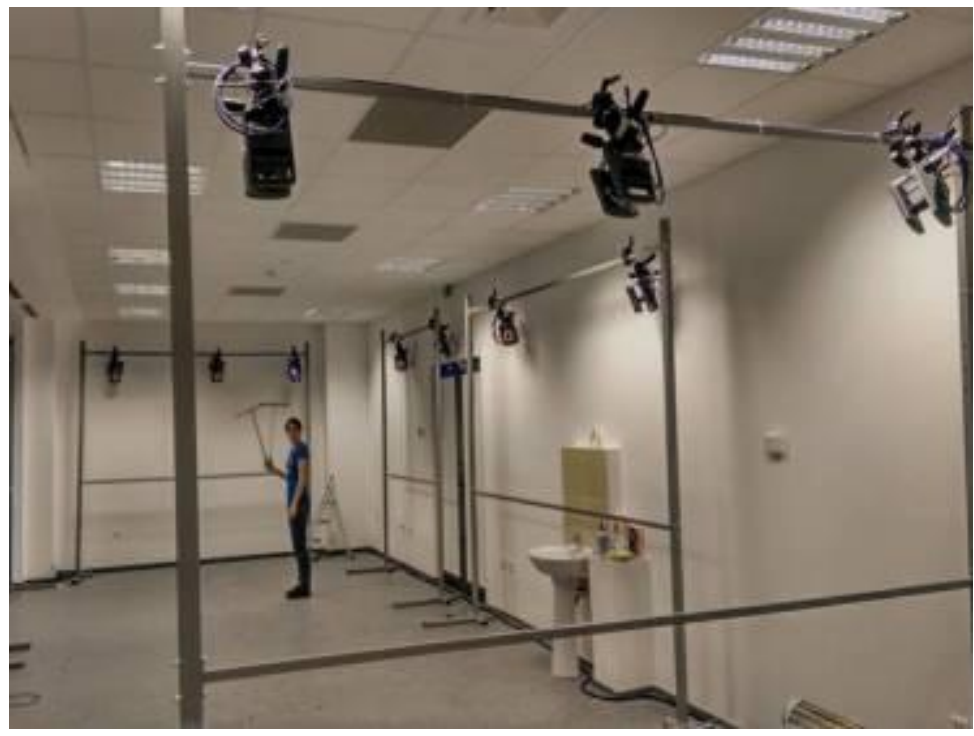

Figure 1. Position of the cameras inside the Laboratory of Innovative Techniques and Processes in Bioengineering (Photo from INCESA Craiova)

This system allows predicting the trajectories of the points scored on the biomechanical system by recording the motion with 14 high-speed cameras (Turner, 2015) (Figure 2).

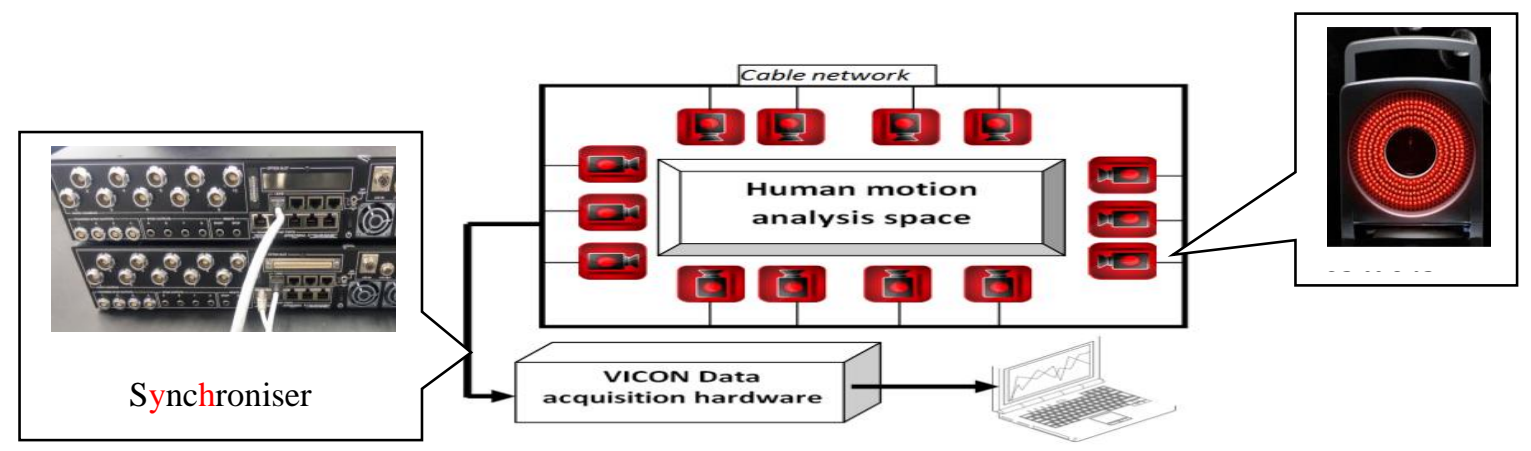

Figure 2. Diagram of the components of the VICON system with its 14 high-speed T/series cameras (Photo from INCESA Craiova)

The 14 cameras are synchronised by a synchroniser (Figure 2). Before starting the measurements, the working space must have certain reference points that are set with the help of fixed led lights arranged in the form of a cross.

Following this procedure, we get a virtual figure of the working space using the 14 synchronised cameras (Figure 3). 
As in all common systems that use video monitoring of motion, the data recording starts from marking the points of the dynamic system that are to be studied. In this research, those points are the main joints of the human body (Zhang et al., 2014, pp. 182-189).

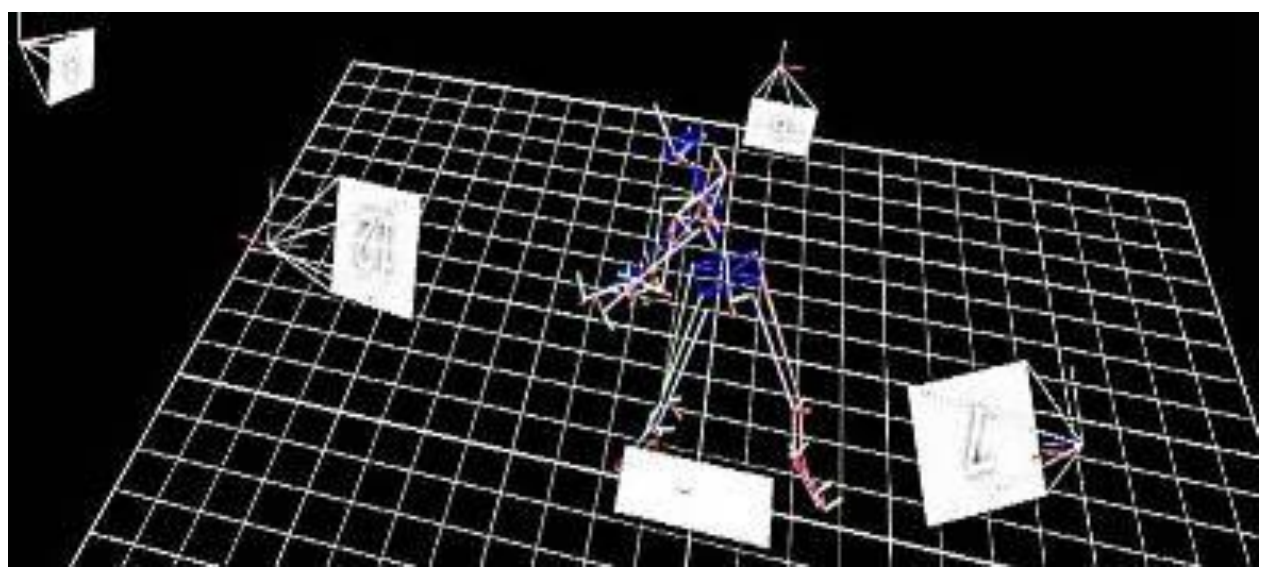

Figure 3. Virtual image of the working space and position of the 14 cameras of the VICON system (Photo: Print screen from the Nexus software, INCESA Craiova)

As part of the experiment, the subject must wear proper clothing, preferably a VICON suit with markers attached to it according to a certain pattern. This is done in order to collect and analyse the data.

Before starting the measurements, the representation of the human body must be generated manually or automatically, as shown in Figure 4.

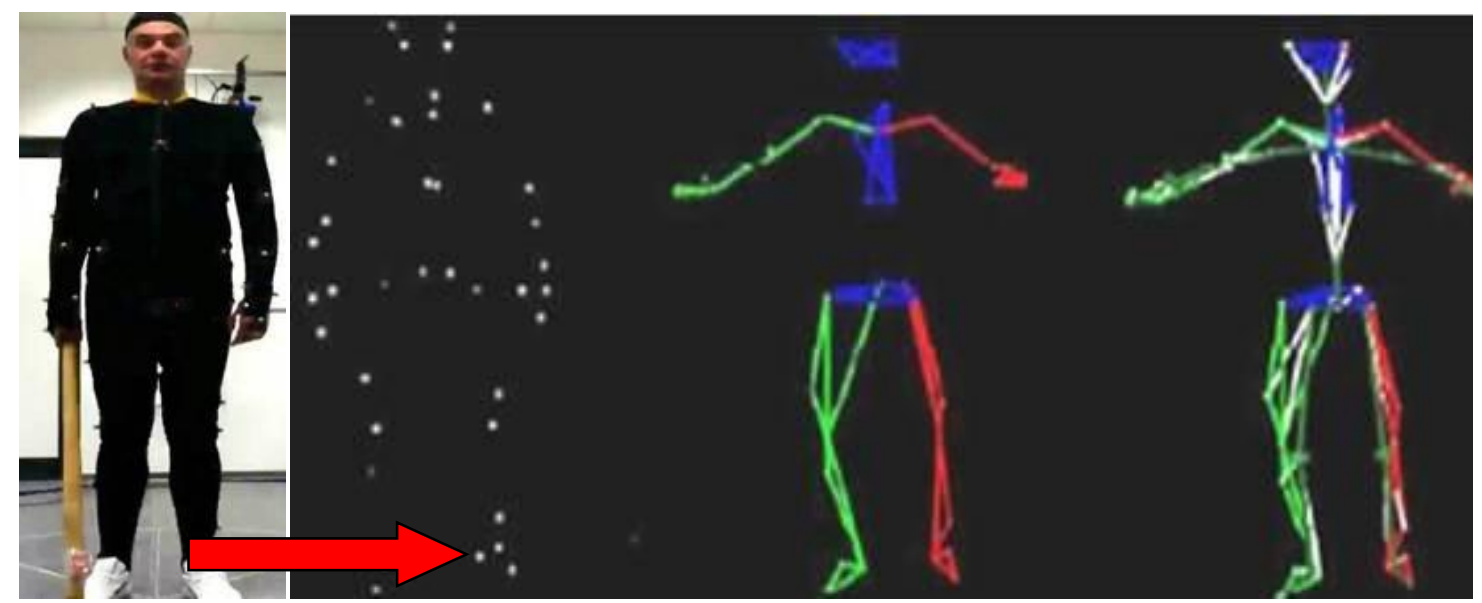

Figure 4. Generating the human exoskeleton with the VICON video system

(Photo: Print screen from the Nexus software, INCESA Craiova)

This is how we labelled the markers by attributing the points marked on the suit or the subject to certain preestablished points from the virtual model, whose trajectories will be recorded on the video capture (Merriaux, Dupuis, Boutteau, Vasseur, \& Savatier, 2017, pp. 1-18) (Figure 5). 
International Proceedings of Human Motricity/ ICPESK 2019 Supplementary Issue of Discobolul - Physical Education, Sport and Kinetotherapy Journal, 2019

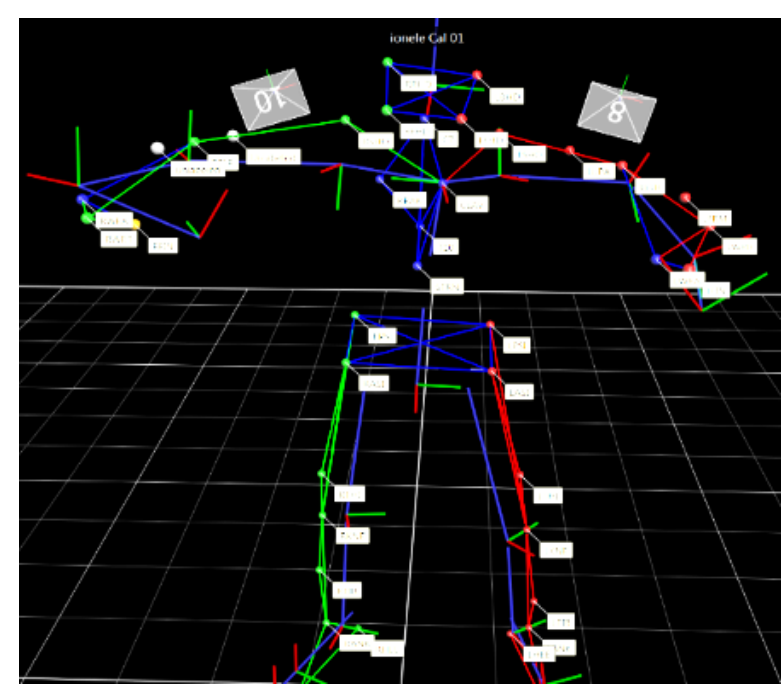

Figure 5. Position of the markers used for a complete analysis of the human subject

(Photo: Print screen from the Nexus software, INCESA Craiova)

\section{Subjects}

We studied the motions of 22 athletes ( 7 boys and 15 girls, average age 30 years for boys and 17 years for girls). The average weight is $64.41 \mathrm{~kg}$ and the average height is $1.68 \mathrm{~m}$.

The values of the main anthropometrical measurements are used to calibrate the VICON system and are presented in Table 1.

Table 1. Values of the main anthropometric parameters of the subjects

\begin{tabular}{lccc}
\hline Subject & Weight $(\mathrm{kg})$ & Height $(\mathrm{m})$ & $\mathrm{BMI}\left(\mathrm{kg} / \mathrm{m}^{2}\right)$ \\
\hline S1 & 87 & 1.75 & 28.40816327 \\
S2 & 59 & 1.72 & 19.94321255 \\
S3 & 78 & 1.75 & 25.46938776 \\
S4 & 92 & 1.92 & 24.95659722 \\
S5 & 83 & 1.77 & 26.49302563 \\
S6 & 92 & 1.9 & 25.48476454 \\
S7 & 84 & 1.76 & 27.11776860 \\
S8 & 32 & 1.44 & 15.43209877 \\
S9 & 53 & 1.6 & 20.70312500 \\
S10 & 62 & 1.65 & 22.77318641 \\
S11 & 60 & 1.7 & 20.76124567 \\
S12 & 60 & 1.7 & 20.76124567 \\
S13 & 53 & 1.69 & 18.55677322 \\
S14 & 53 & 1.64 & 19.70553242 \\
S15 & 68 & 1.68 & 24.09297052 \\
S16 & 53 & 1.61 & 20.44674202 \\
S17 & 50 & 1.6 & 19.53125000 \\
S18 & 53 & 1.64 & 19.70553242 \\
S19 & 52 & 1.6 & 20.31250000 \\
S20 & 49 & 1.63 & 18.44254582 \\
S21 & 54 & 1.67 & 19.36247266 \\
S22 & 90 & 1.57 & 36.51263743 \\
\hline
\end{tabular}


The biomechanical parameters are: trajectory, speed, linear or angular acceleration. These parameters were recorded according to the physical characteristic points of each athlete and their own equipment, i.e., their bats. (Figures 6 and 7)
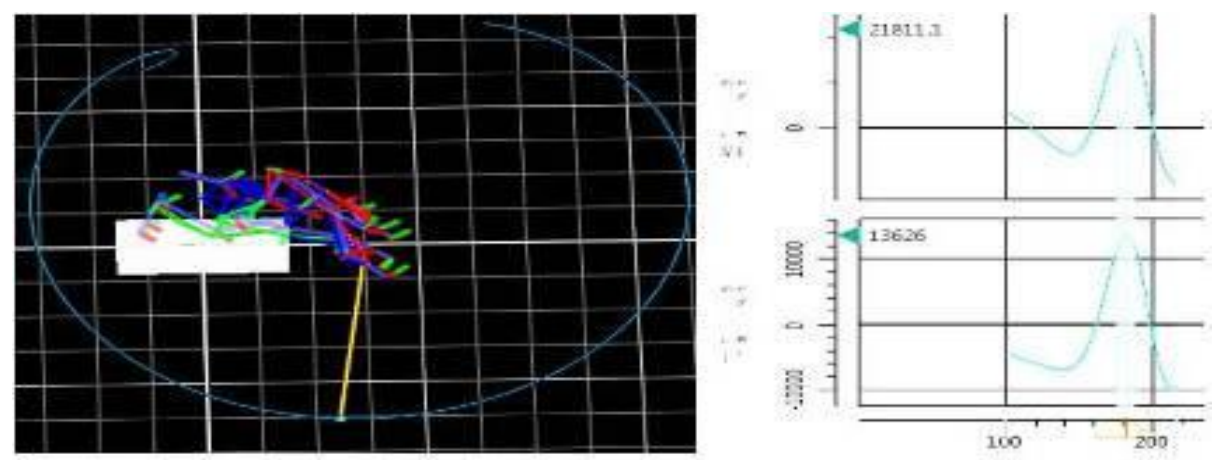

Figure 6. Trajectory of the top of the bat and its position when hitting the ball (Photo: Print screen from the Nexus software, INCESA Craiova)

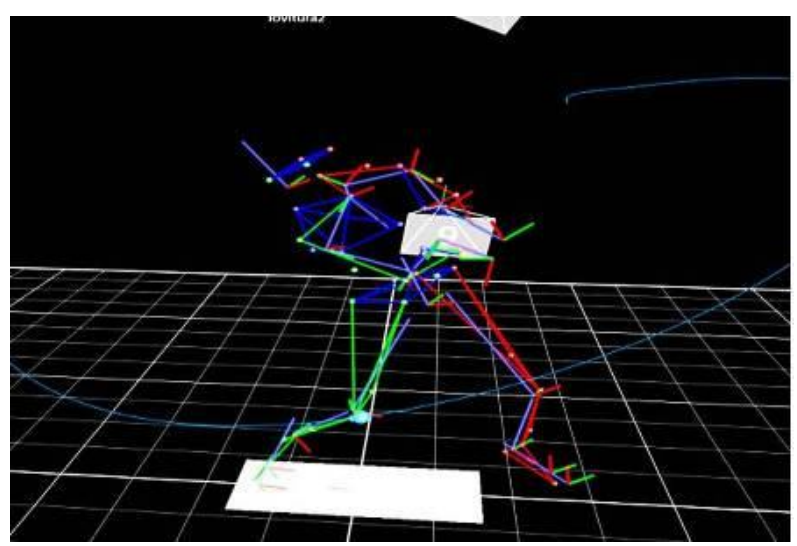

Figure 7. Variation in the speed components of the top of the bat and of the ball with the maximum speed marked along the field ( $\mathrm{x}$ axis) and the height ( $\mathrm{z}$ axis) (Photo: Print screen from the Nexus software, INCESA)

\section{Results}

We recorded the trajectories of the chosen points marked and labelled on the subject's body (Figure 5). The sensors attached to the equipment calculated the data and offered information on the angular amplitude, speed and angular acceleration for those parts involved in the motion of ball hitting with an oina bat.

This study focused on analysing the upper-limb angles that had been previously identified as the most important, with the graphical representation of kinematic parameters just for 1 of the 22 subjects.

- $\quad$ The angle formed between the arm and the trunk for the upper left and right limbs (Figures 8 and 9):

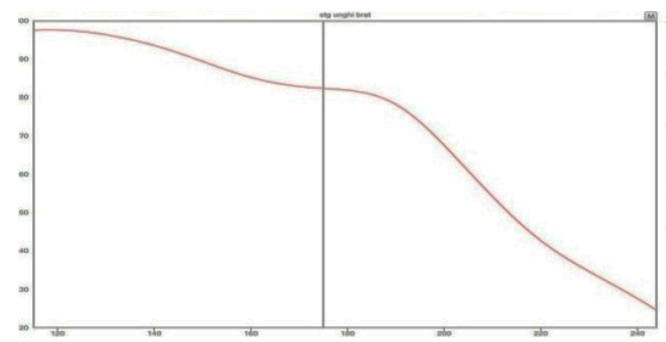

Figure 8. Angle variation for the left arm

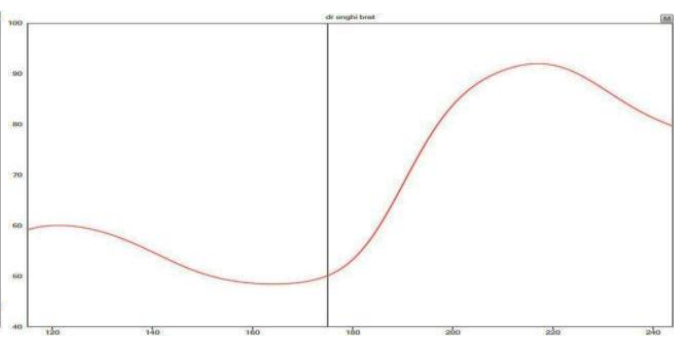

Figure 9. Angle variation for the right arm

- The angle of the elbow for both upper limbs (Figures 10 and 11): 


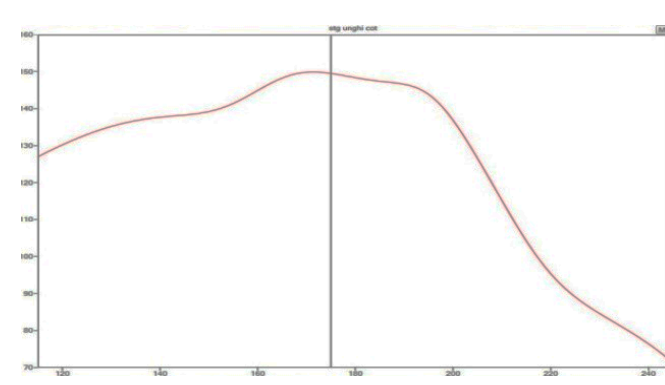

Figure 10. Angle variation for the left elbow

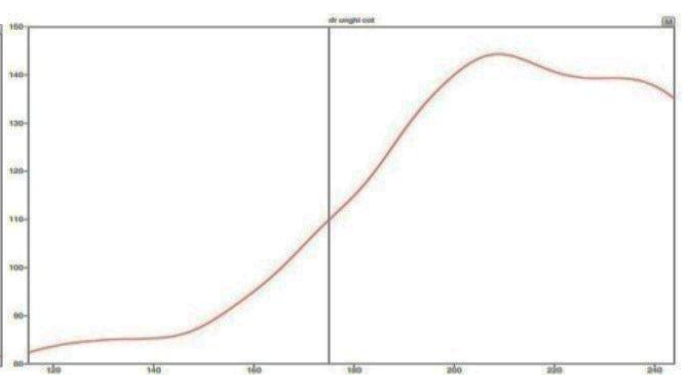

Figure 11. Angle variation for the right elbow

- Angular speed variation in the angle formed by the left and right arms (Figures 12 and 13):

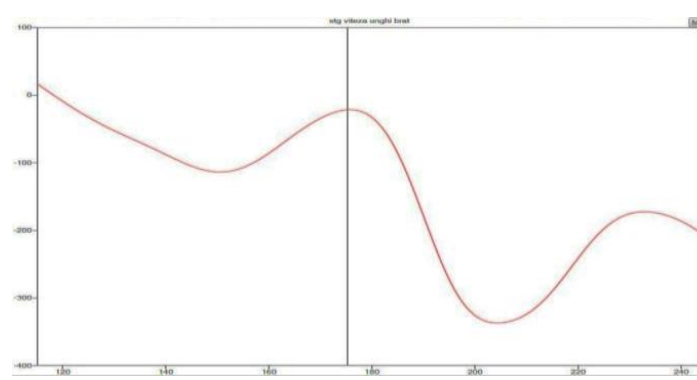

Figure 12. Angular speed variation in the angle of the left arm

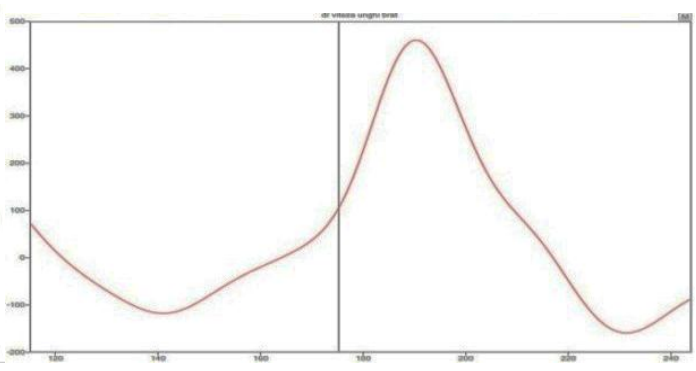

Figure 13. Angular speed variation in the angle of the right arm

- $\quad$ Angular speed variation in the angle formed by the left and right elbows (Figures 14 and 15):

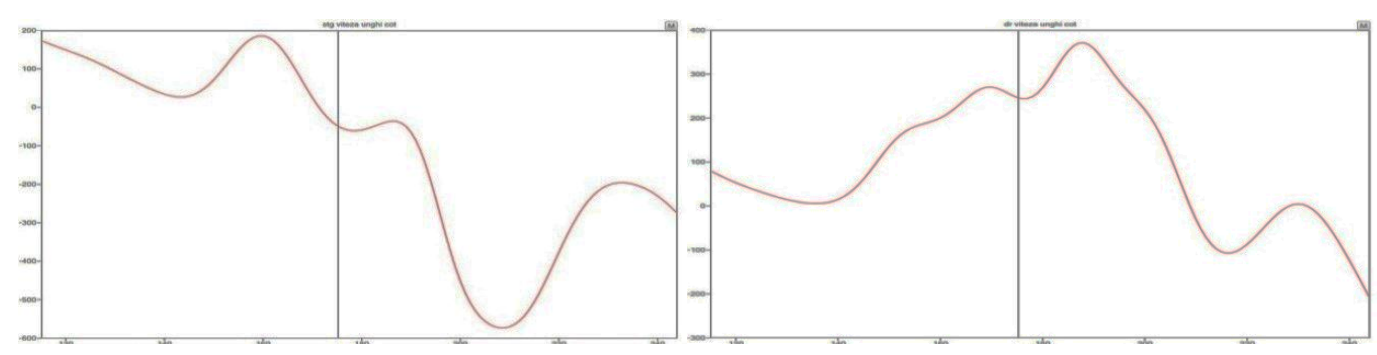

Figure 14. Angular speed variation in the angle Figure 15. Angular speed variation in the angle of the left elbow of the right elbow

- Variation in angular acceleration of the angle formed by the left and right arms (Figures 16 and 17):

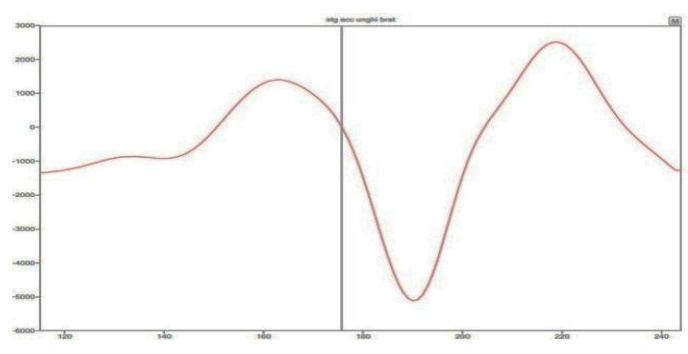

Figure 16. Variation in angular acceleration of the left arm

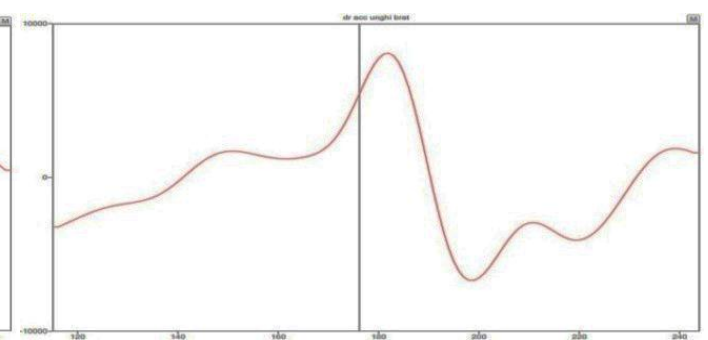

Figure 17. Variation in angular acceleration of the right arm

- Variation in angular acceleration of the angle formed by the left and right elbows (Figures 18 and 19): 
International Proceedings of Human Motricity/ ICPESK 2019

Supplementary Issue of Discobolul - Physical Education, Sport and Kinetotherapy Journal, 2019

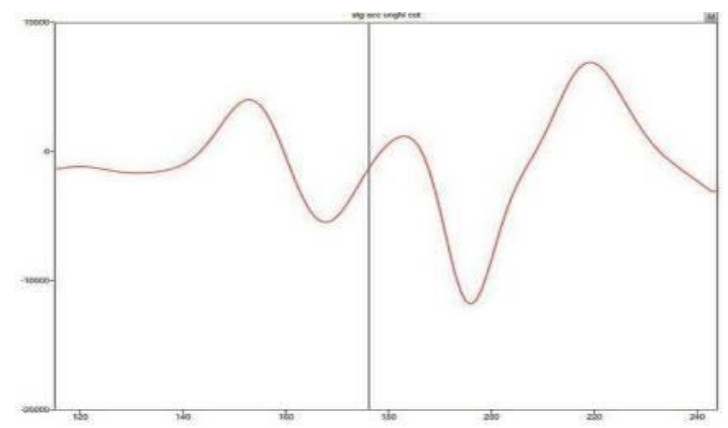

Figure 18. Variation in angular acceleration of the left elbow

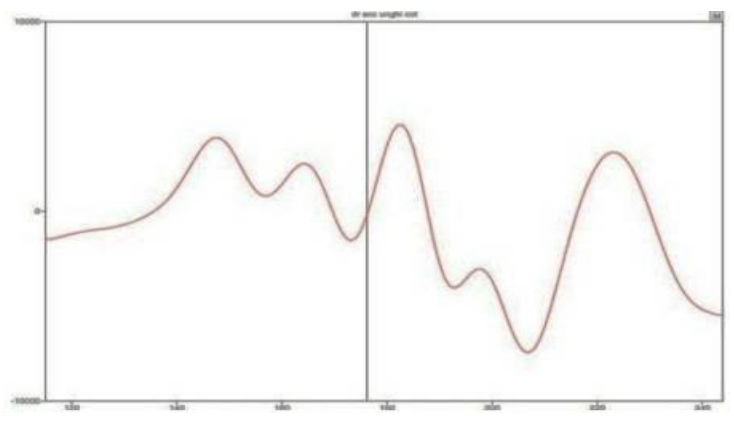

Figure 19. Variation in angular acceleration of the right elbow

The average values of kinematic parameters (amplitude, speed and angular acceleration) are the following:

- the angular amplitude of the left arm is 41.28 degrees (Figure 8), and that of the right arm is 39.28 degrees (Figure 9);

- the angular amplitude of the left elbow is 55.14 degrees (Figure 10) and 73 degrees for the right one (Figure 11);

- the angular speed of the left arm is $347 \mathrm{deg} / \mathrm{s}$ (Figure 12) and $504 \mathrm{deg} / \mathrm{s}$ for the right one (Figure 13);

- the angular speed of the left elbow is $722 \mathrm{deg} / \mathrm{s}$ (Figure 14) and $620 \mathrm{deg} / \mathrm{s}$ for the right one (Figure 15);

- the angular acceleration of the left arm is $7200 \mathrm{deg} / \mathrm{s}$ (Figure 16) and for the right one, $12800 \mathrm{deg} / \mathrm{s} 2$ (Figure 17);

- the angular acceleration of the left elbow is $19300 \mathrm{deg} / \mathrm{s}$ (Figure 18), and for the right one, $20000 \mathrm{deg} / \mathrm{s} 2$ (Figure 19).

\section{Conclusion}

We need to understand the general principles of the mechanics and biomechanics of upper-limb motion based on the previously obtained individual parameters in order to achieve the most efficient technique of hitting the ball in an oina game.

The purpose of this biomechanical research is mainly to understand the variation of kinematic parameters (amplitude, speed and angular acceleration) of the angles created at the level of upper limbs and their influence on the actual hit with the bat during an oina game. The results obtained throughout this research have shown that players have a $31.2 \%$ higher angular speed of the right arm rather than in their left arm and a $14.2 \%$ higher angular speed of the left elbow.

This variation in the values of angular speed between the left and right sides requires the improvement of "explosive" muscle strength in the right arm, which could prevent possible injuries and enhance the kinetic chain of the right limb when referring to strength and speed (Hennessey \& Johnson, 2000).

On the other hand, the left arm needs another type of training to improve isometric strength. This allows the enhancement and stabilisation of the upper left limb, having thus the role of taking over from the strength generated by the collateral segment.

At the same time, the evolution of elbow parameters leads us to the conclusion that it requires the development of explosive strength in the left arm and intense stabilisation through isometrics and isometric stretching of the right arm. When referring to angular values, the arm and elbow muscles must be high (Schaechter et al., 2002). Developing good muscle tone is also essential to maintain the effort during the game, and this can be achieved through a series of training programmes especially conceived to improve explosive strength, since hitting the ball in an oina game is performed in less than a second.

These particular results of the biomechanical analysis of how players hit the ball with a bat can lead to developing a more accurate and personalised training programme in order to achieve the best technique of hitting the ball with the bat so as to score more points and make the difference when playing against an opposing team. 


\section{References}

Buiac, D. (2018). Copilul mic - Nevoia de mişcare, exercițiu fizic și joc [The young child - The need for movement, physical exercise and play]. Bucureşti: Eikon.

Hennessey, W. J., \& Johnson, E. W. (2000). Lower limb orthoses. In Physical medicine and rehabilitation (2 ${ }^{\text {nd }}$ ed.) (pp. 326-352). Philadelphia, PA: W. B. Saunders Co.

Merriaux, P., Dupuis, Y., Boutteau, R., Vasseur, P., \& Savatier, X. (2017). A study of Vicon system positioning performance. Sensors, 17(7): 1591. https://doi.org/10.3390/s17071591

Moje, C., Frangulea, S., Roată, R., \& Şiclovan, L. (2011). Redescoperiţi şi învăţaţi sportul nostru național, oina [Rediscover and learn our national sport, oina]. Constanţa: Muntenia.

Postolache, N. (2009). Fascinația oinei, jocul românilor de pretutindeni [The fascination of oina, the game of Romanians everywhere]. Bucureşti: Profexim.

Rafailescu, Al., \& Oprițescu, C. (1974). Oină [Oina]. Bucureşti: Stadion.

Roată, R. (2018). Oina: Inițierea în jocul de oină [Oina: Initiation into the game of oina]. Suceava: Editura Universității "Ștefan cel Mare".

Schaechter, J. D., Kraft, E., Hilliard, T., Dijkhuizen, R. M., Benner, T., Finklestein, S. P., ... Cramer, S. C. (2002). Motor recovery and cortical reorganization after constraint-induced movement therapy in stroke patients: A preliminary study. Neurorehabilitation and Neural Repair, 16(4), 326-338. https://doi.org/10.1177\%2F154596830201600403

Turner, B. (2015). A search for the perfect golf swing at the University of Derby. Retrieved from https://www.sporttechie.com/search-perfect-golf-swing-university-derby/

VICON. (2015). Retrieved from https://vicon.com/press/2015-12-02/vicon-vantage-helps-derby-university-searchfor-the-perfect-golf-swing

Zhang, J., Sorby, H., Clement, J., David, C., Thomas, L., Hunter, P., ... Besier, T. (2014). The MAP client: Userfriendly musculoskeletal modelling workflows. In F. Bello \& S. Cotin (Eds.), Biomedical simulation (pp. 182192). Springer. 